\title{
LAS REVOLUCIONES DE LA CULTURA ESCRITA. Diálogo e Intervenciones
}

Se habla de la desaparición del libro; yo creo que es imposible. Jorge Luis Borges, El libro, 1978.

\section{Delfina González del Riego Espinosa}

Roger ChARTier $^{1}$ es, tal vez, uno de los historiadores franceses más reconocidos en el ámbito de la historia de la cultura en la actualidad. Ha dedicado gran parte de su carrera a investigar la historia de la vida privada y, particularmente, el mundo de los libros, los editores y los lectores. Su preocupación historiográfica se ha centrado en el estudio de las prácticas de escritura-lectura, los modos de producción de lo escrito (del papiro al códice, del libro a las pantallas), y la apropiación y reconstrucción de significados por parte de los lectores en las diferentes épocas.

El libro que nos ocupa está constituido, fundamentalmente, por un extenso e interesante diálogo que Chartier sostuvo con el periodista francés Jean Lebrun, pero también recopila tres conferencias dictadas en diversos congresos y coloquios, y dos entrevistas publicadas en revistas brasileñas. La aparición de la internet es una

${ }^{1}$ Es director de estudios en LÉcole des Hautes Études en Sciences Sociales de París, director del centro Alexandre Koyré y autor de numerosos libros; entre ellos: El mundo como representación, Libros, lecturas y lectores en la Edad Moderna, y El orden de los libros. 
ocasión propicia para que este prestigioso historiador reflexione sobre la cultura escrita, abordando muy diversos temas: el autor; el editor; los lectores; el rol de las bibliotecas; las censuras; la evolución histórica del libro; los hábitos de lectura, y cómo han evolucionado.

Qué tanto han revolucionado los medios informáticos, la cultura escrita y los hábitos de lectura es, tal vez, la cuestión medular que, con gran acierto, aborda el autor. Chartier nos recuerda que la producción de los libros - $e$ incluso de los textos mismos- es un proceso que va más allá del gesto de la escritura, e implica diferentes momentos, técnicas e intervenciones: las de los autores, los copistas, los libreros editores, los maestros impresores, los cajistas, los correctores, entre otros.

Con base en esta observación, enfatiza el hecho de que a través de la historia se ha escrito y leído de muy distintas maneras. Al respecto, es muy sugerente la figura que nos presenta del autor oral de la antigüedad que dicta sus textos al escriba, diferenciando la función del autor de la del escritor.

Para comprender mejor la verdadera magnitud de esta revolución electrónica, Chartier analiza las grandes innovaciones o revoluciones que ha sufrido la cultura escrita en el pasado. Y concluye que, a su entender, son dos: 1) la primera tiene que ver con el paso del rollo al códice. Esta transformación es muy semejante a las que estamos presenciando ahora, pues permitió, de alguna manera, una conquista de libertad para el lector, en tanto que el nuevo formato le permitía, al mismo tiempo, escribir que leer y tomar distancia, e ir de una página a otra, o de un libro a otro; 2) la segunda revolución tiene que ver con la invención de la imprenta por Gutemberg -a mediados del siglo XV-, que transformó los modos de reproducción de los textos y los de la producción del libro.

La revolución electrónica es mucho más radical porque no sólo modifica la técnica de reproducción del texto, sino también las estructuras y las formas mismas del soporte que transmite a sus lectores. A estas revoluciones del libro, le siguieron también evoluciones en las formas de lectura. La primera de ellas está relacionada con la modalidad física y corporal del acto de leer, cuando se pasa de una lectura oral a una lectura silenciosa. La otra revolución de la lectura tiene que ver con el estilo mismo, que transforma una lectura intensiva en otra extensiva - hacia la mitad del siglo XVIII-. 


\section{LAS REVOLUCIONES DE LA CULTURA ESCRITA}

A esto hay que agregar que cada lector, cada comunidad de lectores tienen sus propios modos de leer, sus maneras de interpretar y de apropiarse de los textos. A partir de esta hipótesis, la historia del libro se convierte, también, en la historia de la o las lecturas que buscan reconstruir las formas contrastadas con las que diferentes lectores aprehendían, manejaban y se apropiaban de los textos contenidos en el libro - algo que, actualmente, está en plena vigencia con la internet-. Finalmente, Chartier nos recuerda que estas revoluciones fueron vividas también como amenazas en su momento; creando, sin embargo, oportunidades y aperturas. 